\title{
R-Modafinil Attenuates Nicotine-Taking and Nicotine-Seeking Behavior in Alcohol-Preferring Rats
}

\author{
Xiao-Fei Wang',3, Guo-Hua Bi ${ }^{1,3}, \mathrm{Yi} \mathrm{He}^{\prime}$, Hong-Ju Yang', Jun-Tao Gao', Oluyomi M Okunola-Bakare ${ }^{2}$, \\ Rachel D Slack ${ }^{2}$, Eliot L Gardner', Zheng-Xiong $X^{*}{ }^{*}$, and Amy Hauck Newman ${ }^{*, 2}$ \\ 'Neuropsychopharmacology Section, Molecular Target and Medications Discovery Branch, National Institute on Drug Abuse, Intramural Research \\ Program, National Institutes of Health, Baltimore, MD, USA; ${ }^{2}$ Medicinal Chemistry Section, Molecular Targets and Medications Discovery Branch, \\ National Institute on Drug Abuse, Intramural Research Program, National Institutes of Health, Baltimore, MD, USA
}

\begin{abstract}
$( \pm$ )-Modafinil (MOD) is used clinically for the treatment of sleep disorders and has been investigated as a potential medication for the treatment of psychostimulant addiction. However, the therapeutic efficacy of ( \pm )-MOD for addiction is inconclusive. Herein we used animal models of self-administration and in vivo microdialysis to study the pharmacological actions of R-modafinil (R-MOD) and S-modafinil (S-MOD) on nicotine-taking and nicotine-seeking behavior, and mechanisms underlying such actions. We found that R-MOD is more potent and effective than S-MOD in attenuating nicotine self-administration in Long-Evans rats. As Long-Evans rats did not show a robust reinstatement response to nicotine, we used alcohol-preferring rats ( $P$-rats) that display much higher reinstatement responses to nicotine than Long-Evans rats. We found that R-MOD significantly inhibited intravenous nicotine self-administration, nicotine-induced reinstatement, and nicotine-associated cue-induced drug-seeking behavior in P-rats. R-MOD alone neither sustained self-administration in P-rats previously self-administering nicotine nor reinstated extinguished nicotine-seeking behavior. The in vivo brain microdialysis assays demonstrated that R-MOD alone produced a slow-onset moderate increase in extracellular DA. Pretreatment with R-MOD dose-dependently blocked nicotine-induced dopamine (DA) release in the nucleus accumbens (NAc) in both naive and nicotine self-administrating rats, suggesting a DA-dependent mechanism underlying mitigation of nicotine's effects. In conclusion, the present findings support further investigation of R-MOD for treatment of nicotine dependence in humans.

Neuropsychopharmacology (2015) 40, 1762-177I; doi:I0.1038/npp.2015.24; published online II February 2015
\end{abstract}

\section{INTRODUCTION}

Tobacco smoking remains a serious global health threat and the single most preventable cause of hospitalizations and deaths in developed countries (Carson et al, 2013). Although many smokers attempt to quit, a majority relapse repeatedly. The United States Food and Drug Administration (FDA) has approved the use of nicotine replacement, bupropion, and varenicline for smoking cessation (Carson et al, 2013). Yet, only $20-30 \%$ of smokers treated with these medications achieve long-term abstinence (Cahill et al, 2007; Carson et al, 2013; Hughes et al, 2007). Therefore, the challenge of developing more effective and/or alternative

*Correspondence: Dr Z-X Xi, Neuropsychopharmacology Section, National Institute on Drug Abuse, Intramural Research Program, National Institutes of Health, 25I Bayview Boulevard, Baltimore, MD 21224, USA, Tel: +I 443740 25I7, Fax: +I 443740 278I, E-mail: zxi@mail.nih.gov or Dr AH Newman, Medicinal Chemistry Section, Molecular Targets and Medications Discovery Branch, National Institute on Drug Abuse, Intramural Research Program, National Institutes of Health, 25I Bayview Boulevard, Baltimore, MD 21224, USA, Tel: +I 443740 2887, Fax: +I 443740 21।I, E-mail: anewman@mail.nih.gov

${ }^{3}$ The first two authors contributed equally to this work. Received 9 September 2014; revised I January 2015; accepted 12 January 2015; accepted article preview online 23 January 2015 medications to achieve smoking cessation and prevent relapse remains critical. One strategy is the preclinical study of medications already clinically available that act on neurobiological mechanisms related to nicotine reward and addiction.

( \pm )-Modafinil (( \pm )-MOD) and its R-enantiomer (R-MOD) are FDA approved for the treatment of narcolepsy and other sleep disorders (Garnock-Jones et al, 2009). ( \pm )-MOD is also used, off label, as a cognitive enhancer and for treatment of attention-deficit/hyperactivity disorder (Schmaal et al, 2013). Recently, ( \pm )-MOD has been clinically investigated for the treatment of cocaine and methamphetamine addiction. As ( \pm )-MOD is a mild psychostimulant and a dopamine transporter (DAT) inhibitor, but with no reported abuse liability (Jasinski and Kovacevic-Ristanovic, 2000; Myrick et al, 2004), it has been suggested as useful for the treatment of psychostimulant dependence. Camacho and Stein (2002) first reported that ( \pm )-MOD was effective in treatment of amphetamine dependence in a patient with comorbid social phobia. This finding was later supported by a number of studies demonstrating that $( \pm)$-MOD was effective in reducing cocaine and methamphetamine use, subjective euphoric effects, craving, and withdrawal symptoms (Dackis et al, 2005; Dackis et al, 2003; Goudriaan et al, 2013; Hart et al, 2008; Malcolm et al, 2006; McGregor et al, 
2008; Shearer et al, 2009). In experimental animals, $( \pm)$-MOD has been reported to block reinstatement of drug-seeking caused by cocaine, heroin, methamphetamine, or drug-associated environmental cues (Mahler et al, 2014; Reichel and See, 2010; Tahsili-Fahadan et al, 2010).

In contrast, several recent clinical trials failed to confirm the therapeutic efficacy of $( \pm)$-MOD in treatment of cocaine (Dackis et al, 2012) or methamphetamine dependence (Anderson et al, 2012; De La Garza et al, 2010; Lee et al, 2013). Similarly, conflicting results are reported for $( \pm)-M O D$ as an adjunctive pharmacotherapeutic aid for smoking cessation. Although $( \pm)$-MOD was reported to attenuate self-reported nicotine 'drug strength,' it had no effect on tobacco withdrawal symptoms (Sofuoglu et al, $2008)$. In two other studies, $( \pm)$-MOD failed to increase tobacco abstinence duration or reduce craving and withdrawal (Perkins et al, 2013; Schnoll et al, 2008).

Given that $( \pm)$-MOD is a mixture of enantiomers and that R-MOD has higher affinity and potency at blocking the DAT (Cao et al, 2010; Loland et al, 2012) and an improved pharmacokinetic (PK) profile (Robertson and Hellriegel, 2003; Wong et al, 1999), we hypothesized that R-MOD may be more potent and effective than S-MOD or $( \pm)$-MOD in attenuating drug-taking and drug-seeking behavior. We tested this hypothesis in this study. We first investigated the effects of R- and S-MOD on nicotine self-administration in Long-Evans rats. As Long-Evans rats failed to display robust reinstatement to nicotine-seeking behavior, we used alcohol-preferring rats (P-rats), which display higher vulnerability to nicotine (Le et al, 2006), to study the effects of R-MOD on nicotine self-administration and relapse to nicotine-seeking behavior. We then evaluated the abuse liability of R-MOD itself in both self-administration and reinstatement tests. Finally, we used in vivo microdialysis to study the effects of R-MOD on nicotineenhanced extracellular DA to explore the mechanisms underlying the above behavioral effects.

\section{MATERIALS AND METHODS}

\section{Subjects}

Male Long-Evans rats (Charles River Laboratories, Raleigh, NC) and P-rats (Indiana University Medical Center, Indianapolis, IN) were used. All animals were housed individually in a climate-controlled room under a $12 \mathrm{~h}$ light/ dark cycle. Food and water were available ad libitum throughout the experiments. All experimental procedures were conducted in accordance with the Guide for the Care and Use of Laboratory Animals and were approved by the Animal Care and Use Committee of the National Institute on Drug Abuse of the US National Institutes of Health.

\section{Drugs}

R-MOD and S-MOD were prepared in the Medicinal Chemistry Section, National Institute on Drug AbuseIntramural Research Program, from intermediates provided by Dr Thomas Prisinzano (University of Kansas) according to literature procedures (Cao et al, 2010). R-MOD and $\mathrm{S}-\mathrm{MOD}$ were dissolved in sterile water containing $10 \%$ DMSO and 15\% Tween-80 for intraperitoneal (i.p.) injec- tion. In the intravenous (i.v.) R-MOD replacement experiment, R-MOD was dissolved in saline.

\section{Experiment 1: Nicotine Self-Administration}

Initial oral sucrose self-administration. The procedures for oral sucrose self-administration were as previously reported (Xi et al, 2006b). Rats were deprived of food and water $2 \mathrm{~h}$ before self-administration and then allowed access to $5 \%$ oral sucrose under fixed ratio-1 (FR-1) reinforcement conditions for 5-7 days ( $3 \mathrm{~h} /$ day). After stable self-administration was achieved, one group of animals was used to study the effects of R-MOD on sucrose self-administration, whereas other groups of rats were used for i.v. nicotine selfadministration below.

Intravenous nicotine self-administration. The procedures for jugular catheter surgery and nicotine selfadministration were as previously reported (Le et al, 2006; $\mathrm{Xi}$ et al, 2006b). Intravenous self-administration experiments were conducted in operant response test chambers from MED Associates (Georgia, VT). Each test chamber had an active lever and an inactive lever. Depression of the active lever activated the infusion pump; depression of the inactive lever was counted but had no consequence. After 7 days of recovery from surgery, rats were initially trained to self-administer nicotine (30 $\mu \mathrm{g} / \mathrm{kg} /$ infusion) under FR-1 reinforcement. Each nicotine infusion delivered a volume of $0.08 \mathrm{ml} /$ infusion over $5 \mathrm{~s}$ and was paired with presentation of a stimulus light and tone. After stable nicotine selfadministration was achieved $(\geq 10$ nicotine infusions per $3 \mathrm{~h}$ session; $<20 \%$ variability in daily nicotine infusions across two consecutive sessions; an active/inactive lever press ratio exceeding $2: 1$ ), some animals were switched to other unit doses of nicotine $(7.5,15,30$, or $60 \mu \mathrm{g} / \mathrm{kg} /$ infusion) under different reinforcement schedules (FR-1, FR-2, or FR-5) to more fully characterize nicotine selfadministration behavior. To confirm whether the operant lever response was reinforced by nicotine, an active/inactive lever switching test was conducted in a subset of rats, in which the previous nicotine-paired active lever became inactive, whereas the previous inactive lever became active. The effects of R- or S-MOD on nicotine self-administration were evaluated in Long-Evans rats and P-rats. After each test, animals then received an additional 3-5 days of selfadministration of nicotine alone until stable self-administration was reestablished. The order of testing for the various doses of R-MOD or S-MOD was counterbalanced.

R-MOD substitution test. After stable nicotine selfadministration was established, an additional group of P-rats was divided into two subgroups ( $n=6$ each): (1) nicotine was replaced by R-MOD $(0.5 \mathrm{mg} / \mathrm{kg} /$ infusion); and (2) nicotine was replaced by saline ( $0.08 \mathrm{ml} /$ infusion). As animals might take several days to support selfadministration for a novel reinforcer, each replacement test was repeated for 3 days. The doses of R-MOD were chosen on two grounds. First, the maximal solubility of R-MOD in saline (vehicle) is $\sim 2 \mathrm{mg} / \mathrm{ml}$, making $0.5 \mathrm{mg} / \mathrm{kg} /$ infusion the maximum feasible unit dose. Second, the cumulative i.v. R-MOD dose within the initial $30 \mathrm{~min}$ was $\sim 2.5-5 \mathrm{mg} / \mathrm{kg}$ 
(5-10 infusions $\times 0.5 \mathrm{mg} / \mathrm{kg} /$ infusion, i.v.), and this is close to or higher than the i.p. dose of $10 \mathrm{mg} / \mathrm{kg}$ of R-MOD that was found to be effective in attenuation of nicotine selfadministration.

\section{Experiment 2: Relapse to Nicotine-Seeking Behavior in P-Rats}

To maximize active lever response during self-administration and reinstatement testing, animals were allowed to selfadminister nicotine (30 or $60 \mu \mathrm{g} / \mathrm{kg} /$ infusion) under progressively increased reinforcement schedules (FR-1-FR-5). After stable nicotine self-administration was established, animals were divided into three groups to evaluate the effects of $\mathrm{R}-\mathrm{MOD}$ in the following experiments.

Nicotine-induced reinstatement. The extinction procedure was the same as described previously (Xi et al, 2006b). During extinction, nicotine was replaced by saline, and the nicotine-associated cue light and tone were turned off. Active lever pressing led only to saline infusion. After the animals met the extinction criteria $(\leq 10$ lever presses for 3 consecutive days), the rats were divided into three subgroups to study the effects of R-MOD on reinstatement of drug-seeking behavior induced by nicotine priming $(0.15 \mathrm{mg} / \mathrm{kg}$, s.c.).

Cue-induced nicotine-seeking behavior. Following establishment of stable nicotine self-administration as described above, the second group of rats underwent 3 weeks of withdrawal in the housing facility. On test day, the rats were placed into the same self-administration chambers to observe cue-induced drug-seeking behavior (i.g., lever pressing) under extinction conditions during which lever pressing resulted in presentation of nicotine-associated cue light and cue tone, but not nicotine. Each rat was tested three times under different R-MOD doses in a counterbalanced manner. The interval between drug tests was 2-3 days.

R-MOD-induced reinstatement. After stable nicotine self-administration was achieved, the third group of rats underwent extinction, as described above, until drugseeking behavior was extinguished. Then, animals were divided into three subgroups and tested for reinstatement of drug-seeking behavior triggered by R-MOD $(0,30$, and $100 \mathrm{mg} / \mathrm{kg}$, i.p.) in P-rats.

\section{Experiment 3: Locomotor Activity in P-Rats}

This experiment was designed to evaluate the psychomotor stimulating effects of R-MOD. Drug-naive rats were placed in locomotor detection chambers (Accuscan, Columbus, $\mathrm{OH})$ and habituated for $1 \mathrm{~h}$. Each rat randomly received vehicle or one dose of R-MOD $(0,30$, and $100 \mathrm{mg} / \mathrm{kg}$, i.p.). Following the injection, locomotor activity was recorded for $2 \mathrm{~h}$ in $10 \mathrm{~min}$ intervals. Each animal was tested 3 times under different R-MOD doses in a counterbalanced manner. The time interval was 2-3 days between tests. The distance counts $(\mathrm{cm})$ were used to evaluate the effects of R-MOD on locomotion.

\section{Experiment 4: In Vivo Microdialysis in P-Rats}

Intracranial guide cannula surgery and in vivo microdialysis procedures were as reported previously (Xi et al, 2006b). Two guide cannulae were surgically implanted into the $\mathrm{NAc}\left(\mathrm{AP}+1.6, \mathrm{ML} \pm 2.0, \mathrm{DV}-4.0 \mathrm{~mm}, 6^{\circ}\right.$ from vertical $)$ to collect extracellular fluid samples. After 7 days of recovery from surgery, microdialysis probes were inserted into the NAc $12 \mathrm{~h}$ before the onset of microdialysis. After $2 \mathrm{~h}$ of baseline sample collection, each animal received one dose of R-MOD (30 and $100 \mathrm{mg} / \mathrm{kg}$, i.p.) and/or nicotine $(0.4 \mathrm{mg} / \mathrm{kg}$, s.c.). R-MOD was given $40 \mathrm{~min}$ before nicotine to observe the effects of R-MOD on nicotine-enhanced extracellular NAc DA. After collection, samples were frozen at $-80^{\circ} \mathrm{C}$. Dialysate DA was measured with the ESA electrochemical detection system (ESA, Chelmsford, MA) (Xi et al, 2006b).

After completion of the microdialysis experiments, rats were deeply anesthetized with a high dose of pentobarbital and perfused transcardially with $0.9 \%$ saline followed by $10 \%$ formalin. Brains were removed and placed in $10 \%$ formalin for histological verification of microdialysis probe locations in rat brain.

\section{Data Analysis}

All data are presented as means \pm SEM. One-way or twoway analysis of variance (ANOVA) for repeated measures over time or drug dose was used to analyze the effects of R-MOD or S-MOD in various experiments. Whenever a significant main effect was found, individual group comparisons were carried out using the StudentNewman-Keuls method.

\section{RESULTS}

\section{R-MOD Inhibits Nicotine Self-Administration in Long-Evans Rats}

Supplementary Figure S1A shows the mean numbers of active and inactive lever responses during daily $3 \mathrm{~h}$ sessions of oral sucrose and i.v. nicotine self-administration in 22 rats displaying stable nicotine self-administration. Thirty four rats were not included as they were either sick, catheter clogged, or did not meet stable nicotine self-administration criteria. Supplementary Figure S1B shows representative nicotine self-administration records from six different animals, illustrating regular patterns of nicotine selfadministration during daily $3 \mathrm{~h}$ sessions. Supplementary Figure S1C shows that R-MOD significantly inhibited nicotine $(30 \mu \mathrm{g} / \mathrm{kg} /$ infusion $)$ self-administration in LongEvans rats in a dose-dependent manner. One-way ANOVA for repeated measures over drug dose demonstrated a statistically significant R-MOD treatment main effect $\left(\mathrm{F}_{4,28}=5.46, p<0.01\right)$. Supplementary Figure S1D shows representative nicotine self-administration records before and after $30 \mathrm{mg} / \mathrm{kg}$ R-MOD administration, illustrating a typical extinction pattern-initial high-rate lever pressing followed by cessation of lever pressing, suggesting a reduction in nicotine rewarding effects. Supplementary Figure S1E shows that $30 \mathrm{mg} / \mathrm{kg}$ R-MOD significantly shifted the nicotine dose-response self-administration curve downward. Two-way ANOVA for repeated measures over nicotine dose revealed a significant R-MOD treatment main 
effect $\left(F_{1,7}=30.99, p<0.001\right)$. Supplementary Figure $\mathrm{S} 1 \mathrm{~F}$ shows that S-MOD, at the same doses $(10-30 \mathrm{mg} / \mathrm{kg})$, had no effect on nicotine self-administration. However, when the dose was increased to $100 \mathrm{mg} / \mathrm{kg}, \mathrm{S}-\mathrm{MOD}$ significantly inhibited nicotine self-administration $\left(\mathrm{F}_{4,24}=5.33\right.$, $p<0.05)$.

\section{Long-Evans Rats Display Low Reinstatement Response to Nicotine}

We then studied whether R-MOD inhibited nicotineinduced reinstatement of drug-seeking behavior. Supplementary Figure S2A shows the active and inactive lever presses during nicotine $(30 \mu \mathrm{g} / \mathrm{kg} /$ infusion $)$ self-administration, extinction, and reinstatement testing, illustrating that nicotine priming $(0.15 \mathrm{mg} / \mathrm{kg}$, s.c. $)$ did not reinstate nicotine-seeking behavior in Long-Evans rats. We then increased the nicotine dose from 30 to $60 \mu \mathrm{g} / \mathrm{kg} /$ infusion during self-administration in an additional group of rats (Supplementary Figure S2B). We again found that nicotine priming failed to reinstate a robust lever response to nicotine in Long-Evans rats.

\section{Alcohol-Preferring Rats Display High Reinstatement Response to Nicotine}

Therefore, we turned to the use of P-rats in this study based on evidence that they display increased vulnerability to nicotine self-administration and relapse to drug seeking (Le et al, 2006). Supplementary Figure S2C shows that P-rats displayed significantly higher active lever responding during self-administration in a reinforcement scheduledependent manner and significantly higher reinstatement responding to nicotine compared to Long-Evans rats, under the same experimental conditions (Supplementary Figure S2B).

\section{R-MOD Inhibits Nicotine Self-Administration in P-Rats}

Nicotine-reinforced self-administration in P-rats was then characterized. Figure 1a shows a typical dose-responserelationship for self-administration a compensatory decrease in lever presses with increased nicotine dose. To determine whether such lever responses were truly reinforced by nicotine, and not by carryover from initial sucrose self-administration, we performed an active and inactive lever switch test in a group of rats. Figure $1 \mathrm{~b}$ shows that P-rats rapidly learnt to press the new active lever for nicotine self-administration while also displaying increased lever responding on the new inactive lever (previous active lever).

Figure 1c shows that R-MOD pretreatment significantly and dose-dependently inhibited nicotine $(60 \mu \mathrm{g} / \mathrm{kg} /$ infusion) self-administration in P-rats (infusions, $\mathrm{F}_{2,14}=$ $15.19, p<0.001$; active lever responses, $F_{2,14}=10.33$, $p<0.001)$. This reduction in nicotine self-administration is not due to nonspecific locomotor impairment, as the same doses of R-MOD neither altered sucrose selfadministration (Figure 1d) nor inhibited locomotor behavior (Supplementary Figure S3). In fact, R-MOD (at $100 \mathrm{mg} / \mathrm{kg}$ ), produced a modest increase in locomotor behavior.

\section{R-MOD Itself Failed to Sustain Self-Administration in P-Rats}

Figure 1e shows that R-MOD substitution for nicotine did not sustain stable self-administration in rats already displaying stable nicotine self-administration. Although there is no significant change observed on the first day of substitution, continuation of substitution for 2 more days caused a significant reduction in the total number of active lever responses. Two-way ANOVA for repeated measures over time revealed a significant time main effect $\left(\mathrm{F}_{10,90}=7.88, p<0.001\right)$, but did not reveal a significant treatment (saline $v s$ R-MOD) main effect $\left(F_{1,9}=0.82\right.$, $p>0.05)$. After cessation of saline or R-MOD replacement testing, nicotine self-administration gradually recovered to the basal levels before the substitution test. Figure if shows representative patterns of self-administration during R-MOD substitution testing, illustrating that the selfadministration behavior underwent gradual extinction over the $3 \mathrm{~h}$ test period. This pattern of extinction was essentially identical to that seen when saline was substituted for nicotine.

\section{R-MOD Inhibits Nicotine- or Cue-Induced Nicotine-Seeking Behavior in P-Rats}

Figure $2 \mathrm{a}$ shows active lever responses during the last session of nicotine self-administration, last session of extinction, and reinstatement testing, illustrating that pretreatment with R-MOD significantly attenuated nicotine-induced reinstatement of drug-seeking behavior $\left(\mathrm{F}_{2,14}=18.09, p<0.001\right)$. R-MOD also significantly inhibited inactive lever responding (Figure $2 \mathrm{~b}$ ).

We also used an animal model of incubation craving (Marchant et al, 2013), in which rats were tested in a single extinction session after 3 weeks of withdrawal to study the effects of R-MOD on nicotine cue-induced drug-seeking behavior. We found that R-MOD pretreatment significantly attenuated nicotine cue-induced drug seeking in P-rats (Figure 2c: $\mathrm{F}_{2,16}=15.21, p<0.001$ ). R-MOD had no effect on inactive lever responses in this test (Figure 2d). Figure $2 \mathrm{e}$ and $2 \mathrm{f}$ shows that R-MOD alone failed to induce reinstatement of nicotine-seeking behavior under the same experimental conditions in additional groups of rats.

\section{R-MOD Blocked Nicotine-Enhanced NAc DA Release}

Figure $3 \mathrm{a}$ shows that systemic injections of R-MOD produced a slow-onset, dose-dependent increase in extracellular NAc DA in naive rats. This effect lasted for 2-3 h with a peak effect at $\sim 1 \mathrm{~h}$ after R-MOD. Two-way ANOVA for repeated measures over time revealed a statistically significant R-MOD treatment main effect $\left(\mathrm{F}_{2,18}=6.01\right.$, $p=0.01)$ and a significant time main effect $\left(\mathrm{F}_{9,18}=4.17\right.$, $p<0.01)$. Post hoc individual group comparisons revealed a statistically significant increase in extracellular DA after $100 \mathrm{mg} / \mathrm{kg}$, but not $30 \mathrm{mg} / \mathrm{kg}$, R-MOD (Figure 3a).

Figure $3 \mathrm{~b}$ shows the time courses of the changes in extracellular DA before and after each drug administration in drug-naive rats, illustrating that both R-MOD and nicotine elevated extracellular DA levels immediately after injection. We then used two methods to quantitatively 
a (Nicotine SA in P-rats, FR1)
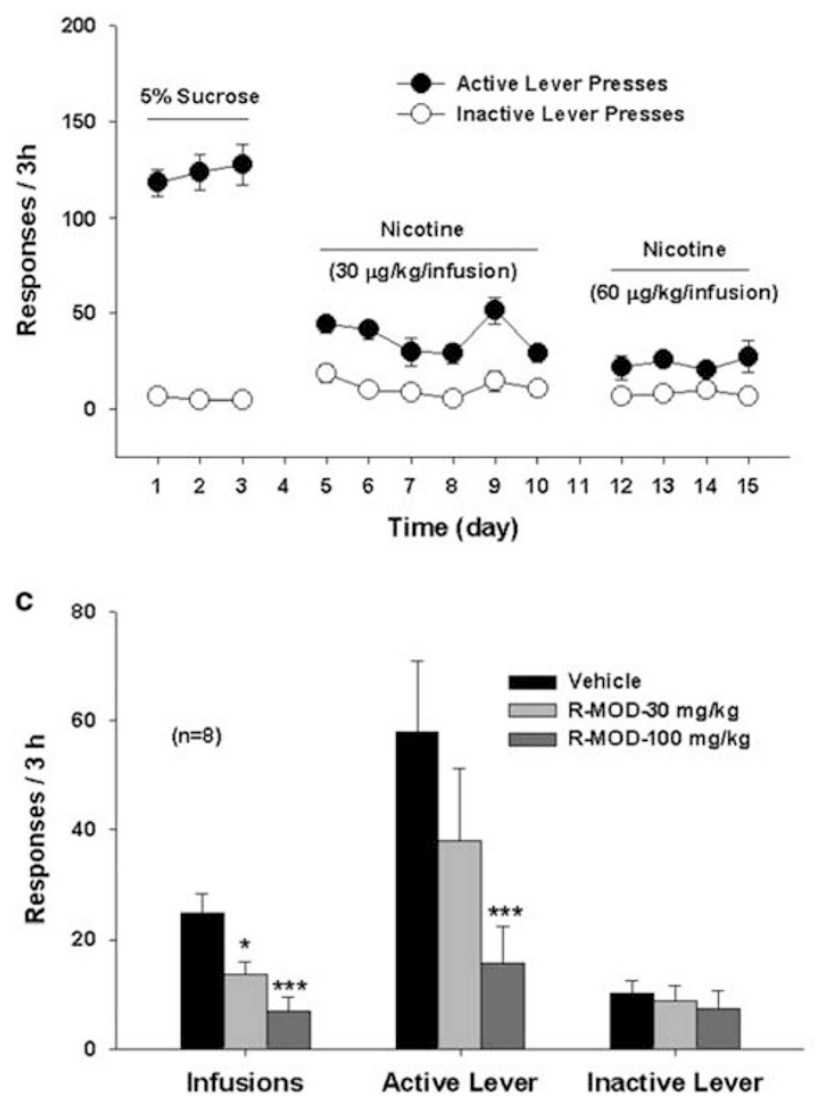

e (R-MOD substitution test)

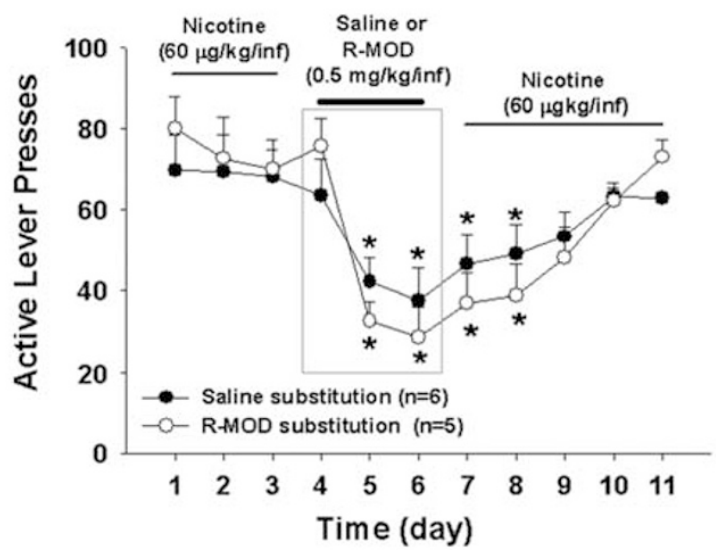

b (Lever Switch Test)
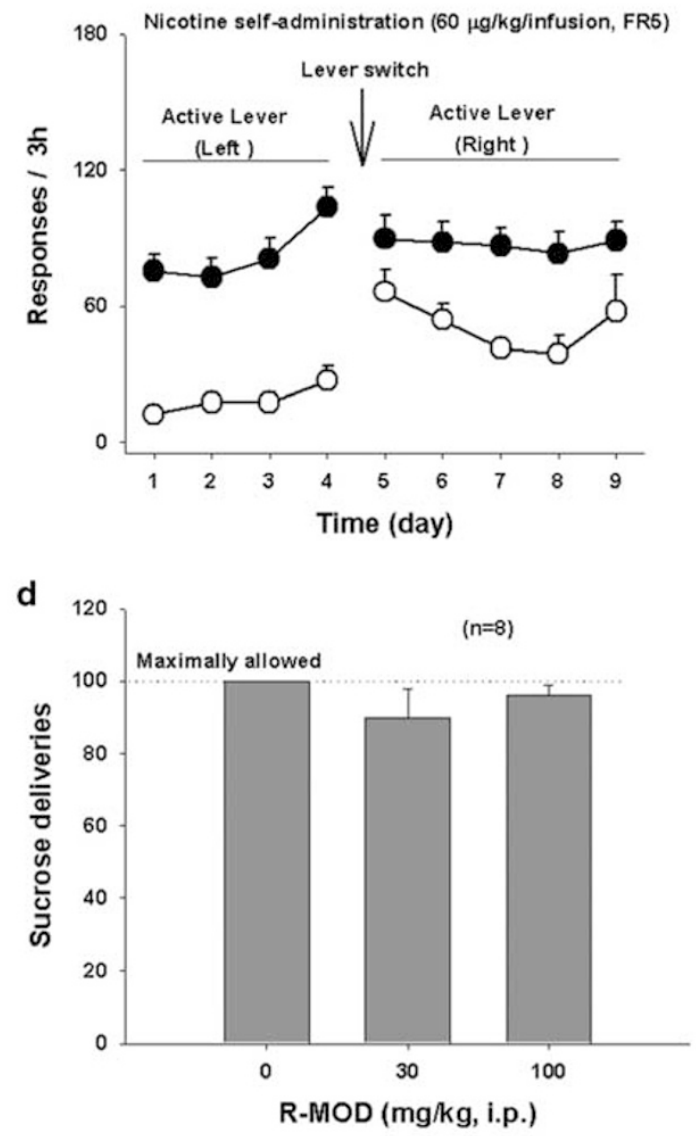

f (Representative self-administration, FR5, Rat \#7)

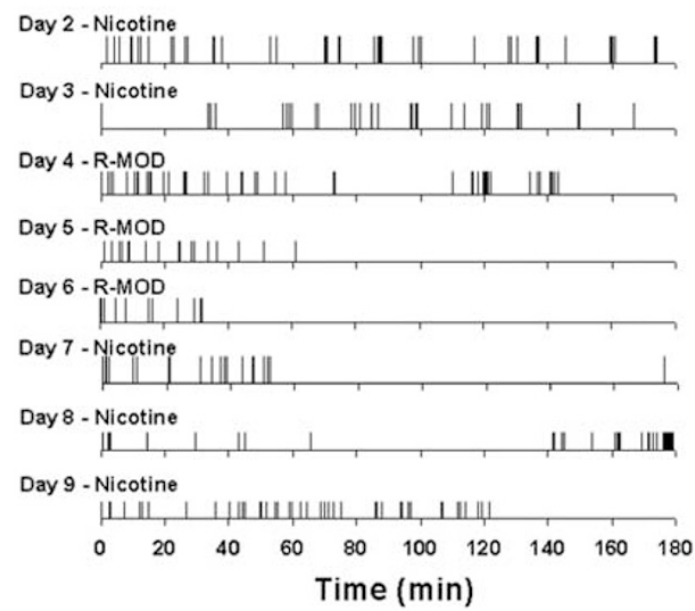

Figure I Effects of R-MOD on nicotine self-administration in P-rats. (a) Stable nicotine self-administration maintained by two different doses (30 or $60 \mu \mathrm{g} / \mathrm{kg} /$ infusion, FR-I) of nicotine in rats pretrained on oral sucrose self-administration; (b) active and inactive lever switch results, illustrating that the lever responses were reinforced by nicotine $(60 \mu \mathrm{g} / \mathrm{kg} /$ infusion, FR-5), not by previous oral sucrose self-administration; (c) R-MOD (30 and I00 mg/kg) dosedependently inhibited nicotine self-administration; (d) R-MOD, at the same doses that inhibited nicotine self-administration, had no effect on oral sucrose self-administration. (e) Active lever presses during nicotine self-administration and 3 days of R-MOD replacement for nicotine, illustrating that R-MOD cannot sustain self-administration in P-rats previously self-administering nicotine. (f) Representative records of nicotine or R-MOD self-administration, illustrating a typical pattern of extinction of drug seeking, ie, initial burst-like lever response followed by cessation of lever responding, during $3 \mathrm{~h}$ test period after R-MOD substitution for nicotine. $* p<0.05$; *** $p<0.00$ I, compared with predrug baseline in each dose group.

evaluate the effects of R-MOD pretreatment on nicotineinduced DA release. First, we compared the absolute amounts of DA (fmol/sample) produced by nicotine in the presence and absence of R-MOD pretreatment (Figure 3c), and found that R-MOD pretreatment significantly attenuated nicotine-enhanced DA in a dose-dependent manner. 


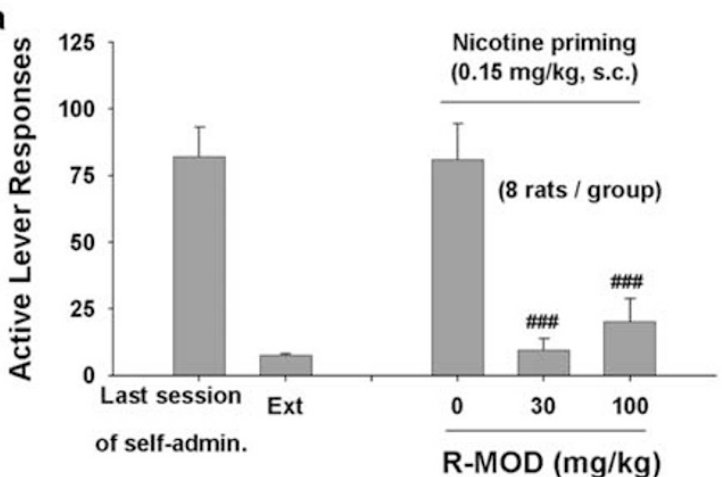

C

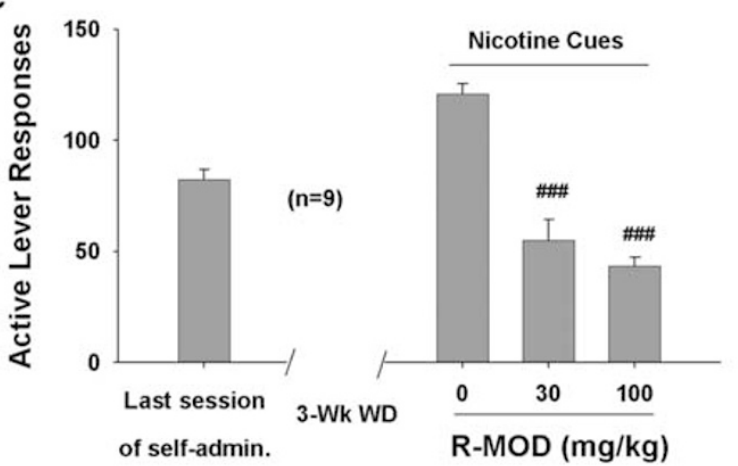

e

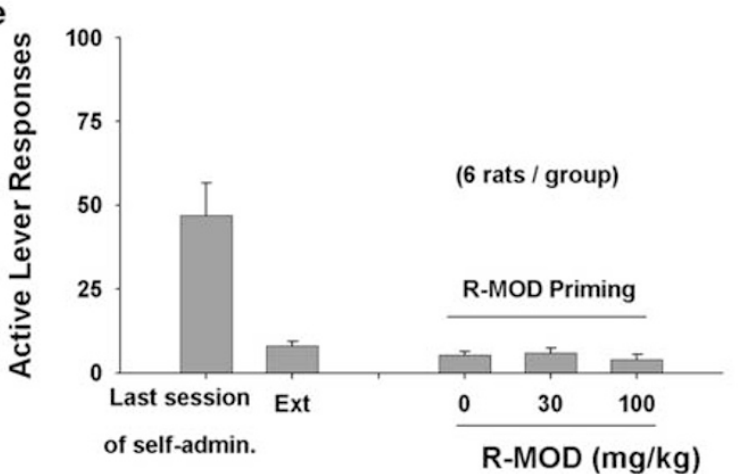

b
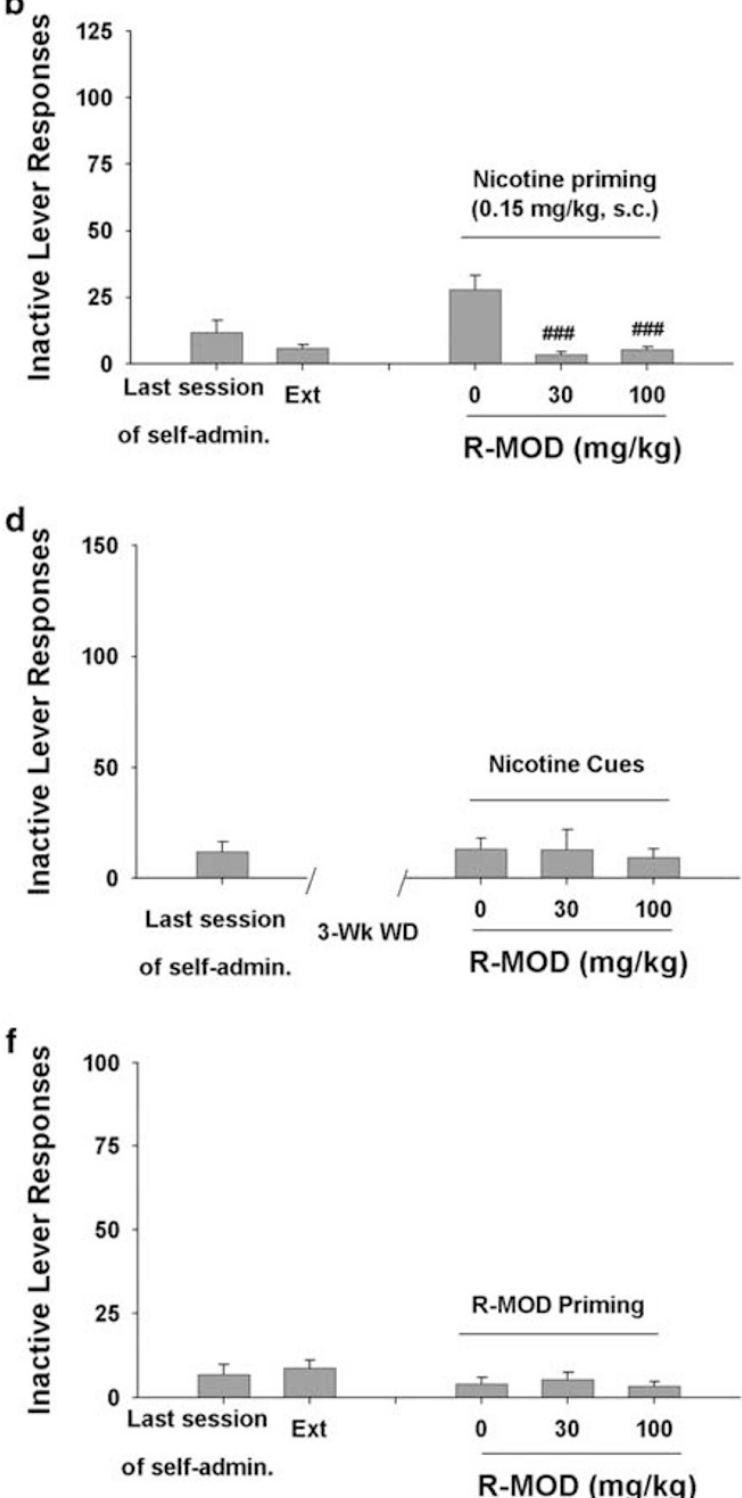

Figure 2 Effects of R-MOD on nicotine- or nicotine-associated cue-induced reinstatement of nicotine seeking in P-rats. (a, b) Active and inactive lever responses during the last session of nicotine self-administration, last session of extinction, and nicotine-triggered reinstatement testing, illustrating that R-MOD significantly inhibited nicotine priming-induced reinstatement. (c, d) Active and inactive lever responses during the last session of nicotine selfadministration and cue-triggered reinstatement testing, illustrating that R-MOD significantly inhibited nicotine-associated cue-induced nicotine-seeking behavior in rats after 3 weeks of withdrawal from the last nicotine self-administration. (e, f) Active and inactive lever responses during the last session of nicotine self-administration, extinction, and reinstatement testing, illustrating that R-MOD (30 or $100 \mathrm{mg} / \mathrm{kg}$ ) failed to reinstate nicotine-seeking behavior.

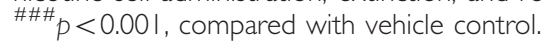

Two-way ANOVA for repeated measures over time did not reveal a statistically significant R-MOD main effect $\left(\mathrm{F}_{2,24}=1.72, p>0.05\right)$, but revealed a statistically significant time main effect $\left(\mathrm{F}_{10,240}=4.90, p<0.001\right)$ and treatment $\times$ time interaction $\left(\mathrm{F}_{10,240}=3.98, p<0.05\right)$. Individual group comparisons revealed a significant reduction in peak DA at $60 \mathrm{~min}$ compared with vehicle control group (Figure $3 \mathrm{c}$ ). Second, we compared nicotine-induced \% changes in DA over baseline in the presence or absence of R-MOD pretreatment (Figure 3d). We found that R-MOD pretreatment significantly blunted nicotine-induced increases in extracellular DA (Figure 3d). Two-way ANOVA for repeated measures over time did not reveal a statistically significant
R-MOD main effect $\left(\mathrm{F}_{2,24}=1.12, p>0.05\right)$, but revealed a statistically significant time main effect $\left(\mathrm{F}_{10,240}=5.89\right.$, $p<0.001)$ and treatment $\times$ time interaction $\left(\mathrm{F}_{10,240}=3.23\right.$, $p<0.05)$. Individual group comparisons revealed a significant reduction in DA at several time points compared with vehicle control group (Figure 3d).

Finally, we investigated the effects of R-MOD pretreatment on nicotine-induced DA enhancement in nicotine selfadministration rats after 2 weeks of withdrawal (Figure 4a). Figure $4 \mathrm{~b}$ shows extracellular DA levels before and after $\mathrm{R}-\mathrm{MOD}$ and/or nicotine administration. As R-MOD pretreatment elevated extracellular DA before the nicotine injection, we used the same methods, as described above, to 

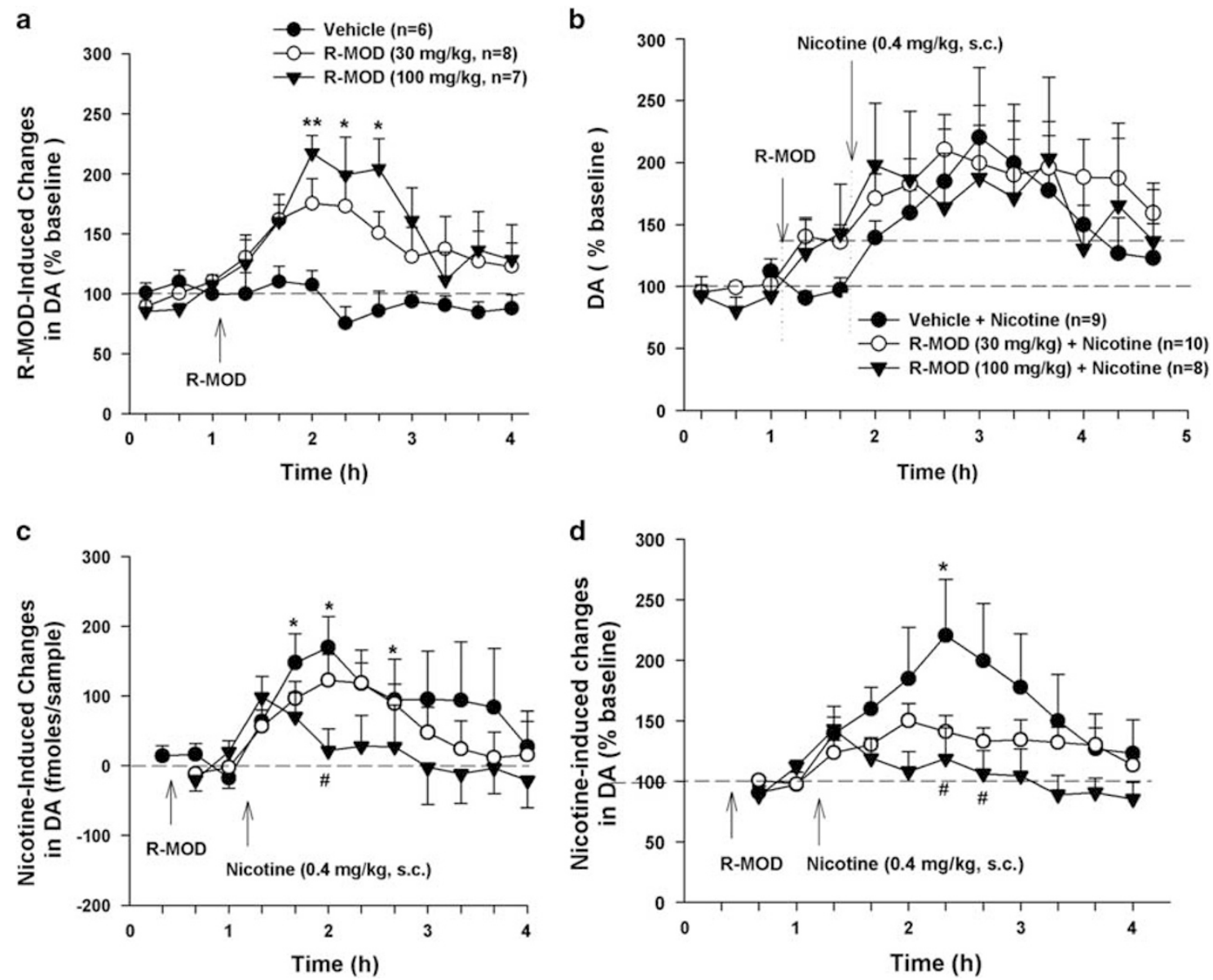

Figure 3 Effects of R-MOD on basal and nicotine-enhanced DA in the nucleus accumbens in naive rats without nicotine self-administration history. (a) R-MOD alone produced a slow-onset, dose-dependent increase in extracellular DA; (b) extracellular DA levels before and after R-MOD and/or nicotine administration, illustrating that each drug elevated extracellular DA levels. (c) Nicotine-induced changes in extracellular NAc DA (fmol/sample) in the presence or absence of R-MOD pretreatment, by subtracting basal level (mean value of two samples before nicotine) of extracellular DA from DA level after nicotine administration; (d) nicotine-induced \% changes in DA over baseline (mean value of two samples before nicotine injection) in the presence or absence of R-MOD pretreatment, illustrating a significant reduction in nicotine-enhanced extracellular DA in a dose-dependent manner after R-MOD administration. ${ }^{*} p<0.05$; ${ }^{*} p<0.01$, compared with baseline before R-MOD (a) or nicotine (b, c) administration; ${ }^{*} p<0.05$, compared with vehicle control group.

quantitatively evaluate nicotine-induced DA release in the absence or presence of R-MOD pretreatment. We found that R-MOD pretreatment significantly and dose-dependently blocked nicotine-enhanced extracellular DA, as assessed by absolute amounts of DA release (Figure $4 \mathrm{c}, \mathrm{F}_{2,16}=7.11$, $p<0.01$, two-way repeated measures ANOVA over time) or percentage changes over the new baseline immediately before nicotine administration (Figure $4 \mathrm{~d}, \mathrm{~F}_{2,16}=9.27$, $p<0.01)$. Histological examination indicated that active microdialysis membranes spanned the length of the core and shell compartments of the NAc (Supplementary Figure S4).

\section{DISCUSSION}

The major findings in this study include: (1) R-MOD is more potent and effective than S-MOD at attenuating nicotine selfadministration in Long-Evans rats; (2) P-rats display higher lever responses for nicotine self-administration and higher reinstatement responses to nicotine priming than Long-
Evans rats; (3) R-MOD effectively attenuates nicotine selfadministration, nicotine-induced reinstatement, and cueinduced nicotine-seeking in P-rats; (4) R-MOD substitution for nicotine fails to sustain self-administration and R-MOD alone also fails to reinstate nicotine-seeking behavior; and (5) pretreatment with R-MOD attenuates nicotine-enhanced DA release in drug-naive rats and nicotine self-administering rats. Together, these findings demonstrate that R-MOD inhibits nicotine-taking and nicotine-seeking behavior in experimental animals, an effect likely mediated by a DAdependent mechanism.

R-MOD and S-MOD display different pharmacokinetic and pharmacodynamic profiles and one might affect the other in the racemic mixture. Specifically, R-MOD has a $\sim 3$-fold higher affinity for the DAT than S-MOD (Cao et al, 2010; Loland et al, 2012) and is more metabolically stable and longer acting (Dinges et al, 2006; Garnock-Jones et al, 2009). In addition, R-MOD appears to bind to the DAT more like atypical DA uptake inhibitors, exemplified by JHW 007, than like cocaine (Loland et al, 2012; OkunolaBakare et al, 2014). In this study, we found that R-MOD is 
a
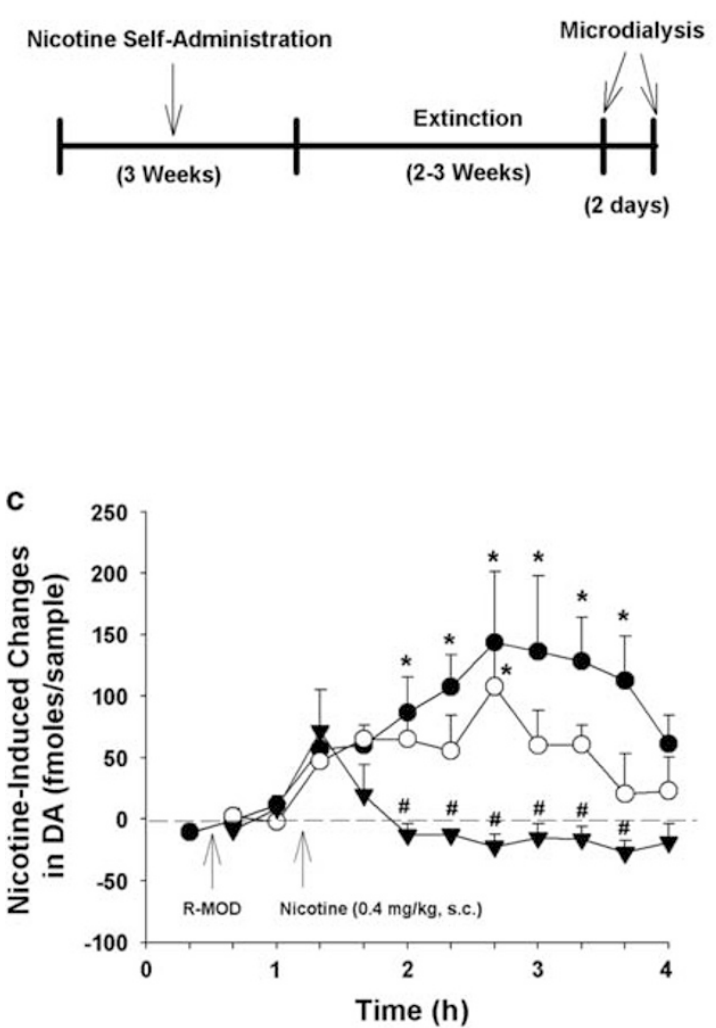

b

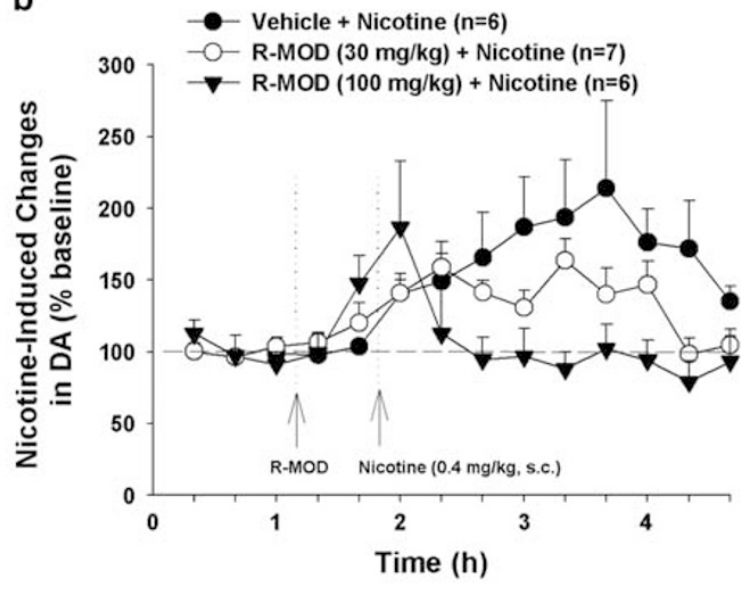

d

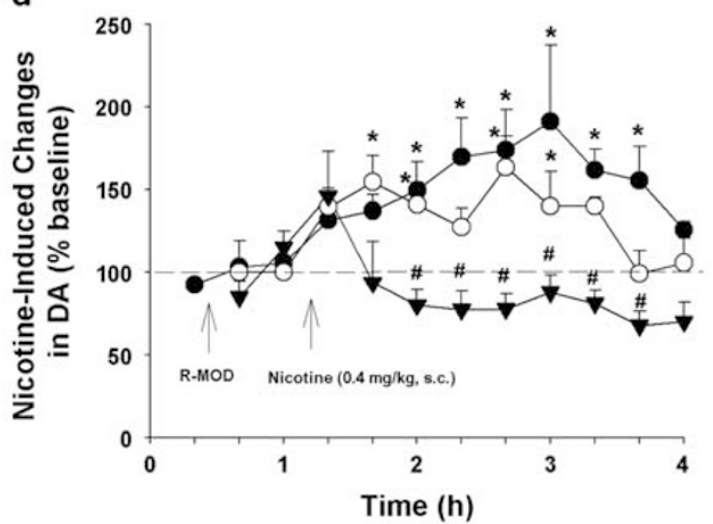

Figure 4 Effects of R-MOD on basal and nicotine-enhanced DA in the nucleus accumbens in rats with nicotine self-administration history. (a) The general experimental procedures; (b) extracellular DA levels before and after R-MOD and/or nicotine administration, illustrating that both drugs elevated extracellular DA levels. (c) Nicotine-induced changes in extracellular NAc DA (fmol/sample) in the presence or absence of R-MOD pretreatment, by subtracting basal level (mean value of two samples before nicotine) of extracellular DA from DA level after nicotine administration; (d) nicotine-induced \% changes in DA over baseline (mean value of two samples before nicotine injection) in the presence or absence of R-MOD pretreatment, illustrating a significant reduction in nicotine-enhanced extracellular DA in a dose-dependent manner after R-MOD administration. * $p<0.05$; compared with baseline before R-MOD (a) or nicotine (b, c) administration; ${ }^{\#} p<0.05$, compared with vehicle control group.

more effective than S-MOD in inhibiting nicotine selfadministration in Long-Evans rats. The minimum effective doses $(10-30 \mathrm{mg} / \mathrm{kg})$ of R-MOD in attenuating nicotine selfadministration and relapse to nicotine seeking are also significantly lower than that of $( \pm)$-MOD $(300 \mathrm{mg} / \mathrm{kg})$ in attenuating cocaine-, methamphetamine-, or cue-induced reinstatement of drug-seeking behavior (Deroche-Gamonet et al, 2002; Holtz et al, 2012; Mahler et al, 2014; Reichel and See, 2010). We note that the effective doses of R-MOD in inhibiting nicotine self-administration are higher in P-rats $(30-100 \mathrm{mg} / \mathrm{kg})$ than in Long-Evans rats $(10-30 \mathrm{mg} / \mathrm{kg})$. This may be related to the higher nicotine dose used in the P-rats $(60 \mu \mathrm{g} / \mathrm{kg} /$ infusion $)$ than that used in the Long-Evans rats $(30 \mu \mathrm{g} / \mathrm{kg} /$ infusion $)$. We also note that $( \pm)$-MOD produces conditioned place preference (Nguyen et al, 2011; Shuman et al, 2012). However, in this study, R-MOD substitution failed to sustain self-administration in rats previously self-administering nicotine. R-MOD itself also failed to reinstate drug-seeking behavior, suggesting that R-MOD has significantly lower abuse potential than nicotine. This may be related to the lower (10- to 20-fold) affinity of R-MOD for the DAT than cocaine, and different pharmacokinetic and pharmacodynamic profiles (Gold and Balster, 1996; Loland et al, 2012; Newman et al, 2010; Paterson et al, 2010). Taken together, the present findings suggest that R-MOD may be more useful than ( \pm )-MOD in treatment of substance abuse and addiction, and should be investigated for smoking cessation.

Although the present findings are observed mainly in selectively bred P-rats, they may generalize to other populations of rats or humans as R-MOD is also effective in attenuating nicotine self-administration in Long-Evans rats, and only a small population of human subjects develop addiction to nicotine, similar to P-rats that display higher vulnerability to nicotine (Le et al, 2006). We acknowledge that only a $3 \mathrm{~h}$ short access to nicotine was used in the present nicotine self-administration, and this may not reflect certain key aspects of the nicotine addiction state in a manner seen after more prolonged daily nicotine consumption.

The mechanisms by which R-MOD inhibits nicotinetaking and nicotine-seeking behaviors are unclear. It is 
unlikely due to nonspecific sedation or locomotor impairment as R-MOD neither alters oral sucrose self-administration nor inhibits locomotor behavior. In contrast, $\mathrm{R}-\mathrm{MOD}$, at the high dose of $100 \mathrm{mg} / \mathrm{kg}$, moderately increased open-field locomotor activity. This is consistent with previous findings that $( \pm)$-MOD facilitates expression of locomotor sensitization and increased locomotor activity in rodents (Edgar and Seidel, 1997; Paterson et al, 2010). Although $( \pm)$-MOD may modulate multiple neurotransmitter systems, the DAT is the only target that has been directly implicated in its therapeutic efficacy (Loland et al, 2012; Mereu et al, 2013 for review). An important finding in this study is that R-MOD pretreatment significantly blocks nicotine-enhanced DA in the NAc in either drug-naive rats or nicotine self-administering rats, suggesting a DAdependent mechanism underlying the behavioral effects observed in this study. In addition, systemic administration of R-MOD alone also elevated NAc DA. This effect has been attributed to its DAT inhibition (Loland et al, 2012). As virtually all drug-dependent humans and experimental animals display reduced basal levels of extracellular DA or DA receptor (particularly D2/3) densities after abstinence (Diana, 2011; Volkow et al, 2009), this hypofunctional NAc DA transmission has been postulated to be correlated with increased drug craving and increased susceptibility to relapse (Diana, 2011; Volkow et al, 2009). Accordingly, the R-MOD-induced increase in extracellular DA would be expected to renormalize extracellular DA, and therefore contribute to relief of nicotine craving and relapse to nicotine-seeking behavior. The mechanisms by which R-MOD inhibits nicotine-enhanced DA are unclear. One possibility is that R-MOD-induced increases in basal levels of DA may activate presynaptic DA (D2 and D3) autoreceptors, therefore inhibiting subsequent nicotineenhanced DA. Thus, reduced DA response to nicotine, combined with normalized extracellular DA produced by R-MOD pretreatment, may explain the antagonism of nicotine self-administration and relapse to nicotine-seeking behavior after R-MOD administration.

In conclusion, this study demonstrates that low doses of R-MOD significantly inhibit nicotine-taking and nicotineseeking behavior in rats. As R-MOD itself has lower reinforcing effects than nicotine, the present preclinical findings support clinical investigation of R-MOD as a promising medication for treatment of nicotine dependence in humans.

\section{FUNDING AND DISCLOSURE}

The authors declare no conflict of interest.

\section{ACKNOWLEDGEMENTS}

This research was supported by the Intramural Research Program (IRP) of the National Institute on Drug Abuse (NIDA), National Institutes of Health (NIH). We acknowledge Ms J Cao for synthesizing S-MOD, Dr Tom Prisinzano for supplying intermediates and methods for the syntheses of R- and S-modafinil, and Drs Yavin Shaham and Gianluigi Tanda for their helpful suggestions on experimental design and comments on an earlier draft of this manuscript.

\section{REFERENCES}

Anderson AL, Li SH, Biswas K, McSherry F, Holmes T, Iturriaga E et al (2012). Modafinil for the treatment of methamphetamine dependence. Drug Alcohol Depend 120: 135-141.

Cahill K, Stead LF, Lancaster T (2007). Nicotine receptor partial agonists for smoking cessation. Cochrane Database Syst Rev 4: CD006103.

Camacho A, Stein MB (2002). Modafinil for social phobia and amphetamine dependence. Am J Psychiatry 159: 1947-1948.

Cao J, Prisinzano TE, Okunola OM, Kopajtic T, Shook M, Katz JL et al (2010). Structure-activity relationships at the monoamine transporters for a novel series of modafinil (2-[(diphenylmethyl)sulfinyl]acetamide) analogues. ACS Med Chem Lett 2: 48-52.

Carson KV, Brinn MP, Robertson TA, To ANR, Esterman AJ, Peters $M$ et al (2013). Current and emerging pharmacotherapeutic options for smoking cessation. Subst Abuse 7: 85-105.

Dackis CA, Kampman KM, Lynch KG, Pettinati HM, O’Brien CP (2005). A double-blind, placebo-controlled trial of modafinil for cocaine dependence. Neuropsychopharmacology 30: 205-211.

Dackis CA, Kampman KM, Lynch KG, Plebani JG, Pettinati HM, Sparkman T et al (2012). A double-blind, placebo-controlled trial of modafinil for cocaine dependence. J Subst Abuse Treat 43: $303-312$.

Dackis CA, Lynch KG, Yu E, Samaha FF, Kampman KM, Cornish JW et al (2003). Modafinil and cocaine: a double-blind, placebo-controlled drug interaction study. Drug Alcohol Depend 70: 29-37.

De La Garza R 2nd, Zorick T, London ED, Newton TF (2010). Evaluation of modafinil effects on cardiovascular, subjective, and reinforcing effects of methamphetamine in methamphetamine-dependent volunteers. Drug Alcohol Depend 106: 173-180.

Deroche-Gamonet V, Darnaudery M, Bruins-Slot L, Piat F, Le Moal M, Piazza PV (2002). Study of the addictive potential of modafinil in naive and cocaine-experienced rats. Psychopharmacology 161: 387-395.

Diana M (2011). The dopamine hypothesis of drug addiction and its potential therapeutic value. Front Psychiatry 2: 64 .

Dinges DF, Arora S, Darwish M, Niebler GE (2006). Pharmacodynamic effects on alertness of single doses of armodafinil in healthy subjects during a nocturnal period of acute sleep loss. Curr Med Res Opin 22: 159-167.

Edgar DM, Seidel WF (1997). Modafinil induces wakefulness without intensifying motor activity or subsequent rebound hypersomnolence in the rat. J Pharmacol Exp Ther 283: 757-769.

Garnock-Jones KP, Dhillon S, Scott LJ (2009). Armodafinil. CNS Drugs 23: 793-803.

Gold LH, Balster RL (1996). Evaluation of the cocaine-like discriminative stimulus effects and reinforcing effects of modafinil. Psychopharmacology 126: 286-292.

Goudriaan AE, Veltman DJ, van den Brink W, Dom G, Schmaal L (2013). Neurophysiological effects of modafinil on cue-exposure in cocaine dependence: a randomized placebo-controlled cross-over study using pharmacological fMRI. Addict Behav 38: 1509-1517.

Hart CL, Haney M, Vosburg SK, Rubin E, Foltin RW (2008). Smoked cocaine self-administration is decreased by modafinil. Neuropsychopharmacology 33: 761-768.

Holtz NA, Lozama A, Prisinzano TE, Carroll ME (2012). Reinstatement of methamphetamine seeking in male and female rats treated with modafinil and allopregnanolone. Drug Alcohol Depend 120: 233-237.

Hughes JR, Callas PW, Peters EN (2007). Interest in gradual cessation. Nicotine Tob Res 9: 671-675.

Jasinski DR, Kovacevic-Ristanovic R (2000). Evaluation of the abuse liability of modafinil and other drugs for excessive daytime sleepiness associated with narcolepsy. Clin Neuropharmacol 23: 149-156. 
Le AD, Li Z, Funk D, Shram M, Li TK, Shaham Y (2006). Increased vulnerability to nicotine self-administration and relapse in alcohol-naive offspring of rats selectively bred for high alcohol intake. J Neurosci 26: 1872-1879.

Lee N, Pennay A, Hester R, McKetin R, Nielsen S, Ferris J (2013). A pilot randomised controlled trial of modafinil during acute methamphetamine withdrawal: feasibility, tolerability and clinical outcomes. Drug Alcohol Rev 32: 88-95.

Loland CJ, Mereu M, Okunola OM, Cao J, Prisinzano TE, Mazier S et al (2012). R-modafinil (armodafinil): a unique dopamine uptake inhibitor and potential medication for psychostimulant abuse. Biol Psychiatry 72: 405-413.

Mahler SV, Hensley-Simon M, Tahsili-Fahadan P, Lalumiere RT, Thomas C, Fallon RV et al (2014). Modafinil attenuates reinstatement of cocaine seeking: role for cystine-glutamate exchange and metabotropic glutamate receptors. Addict Biol 19: 49-60.

Malcolm R, Swayngim K, Donovan JL, DeVane CL, Elkashef A, Chiang $\mathrm{N}$ et al (2006). Modafinil and cocaine interactions. Am J Drug Alcohol Abuse 32: 577-587.

Marchant NJ, Li X, Shaham Y (2013). Recent developments in animal models of drug relapse. Curr Opin Neurobiol 23: 675-683.

McGregor C, Srisurapanont M, Mitchell A, Wickes W, White JM (2008). Symptoms and sleep patterns during inpatient treatment of methamphetamine withdrawal: a comparison of mirtazapine and modafinil with treatment as usual. J Subst Abuse Treat 35: 334-342.

Mereu M, Bonci A, Newman AH, Tanda G (2013). The neurobiology of modafinil as an enhancer of cognitive performance and a potential treatment for substance use disorders. Psychopharmacology 229: 415-434.

Myrick H, Malcolm R, Taylor B, LaRowe S (2004). Modafinil: preclinical, clinical, and post-marketing surveillance-a review of abuse liability issues. Ann Clin Psychiatry 16: 101-109.

Nguyen TL, Tian YH, You IJ, Lee SY, Jang CG.Modafinil-induced conditioned place preference via dopaminergic system in mice. Synapse (2011; 65: 733-741.

Newman JL, Negus SS, Lozama A, Prisinzano TE, Mello NK (2010). Behavioral evaluation of modafinil and the abuse-related effects of cocaine in rhesus monkeys. Exp Clin Psychopharmacol 18: 395-408.

Okunola-Bakare OM, Cao J, Kopajtic T, Katz JL, Loland CJ, Shi L et al (2014). Elucidation of structural elements for selectivity across monoamine transporters: novel 2-[(diphenylmethyl)sulfinyl]acetamide (modafinil) analogues. J Med Chem 57: 1000-1013.

Paterson NE, Fedolak A, Olivier B, Hanania T, Ghavami A, Caldarone B (2010). Psychostimulant-like discriminative stimulus and locomotor sensitization properties of the wakepromoting agent modafinil in rodents. Pharmacol Biochem Behav 95: 449-456.

Perkins KA, Lerman C, Karelitz JL, Jao NC, Chengappa KN, Sparks GM (2013). Sensitivity and specificity of a procedure for early human screening of novel smoking cessation medications. Addiction 108: 1962-1968.

Reichel CM, See RE (2010). Modafinil effects on reinstatement of methamphetamine seeking in a rat model of relapse. Psychopharmacology 210: 337-346.

Robertson P Jr, Hellriegel ET (2003). Clinical pharmacokinetic profile of modafinil. Clin Pharmacokinet 42: 123-137.

Schmaal L, Goudriaan AE, Joos L, Kruse AM, Dom G, van den Brink W et al (2013). Modafinil modulates resting-state functional network connectivity and cognitive control in alcohol-dependent patients. Biol Psychiatry 73: 789-795.

Schnoll RA, Wileyto EP, Pinto A, Leone F, Gariti P, Siegel S et al (2008). A placebo-controlled trial of modafinil for nicotine dependence. Drug Alcohol Depend 98: 86-93.

Shearer J, Darke S, Rodgers C, Slade T, van Beek I, Lewis J et al (2009). A double-blind, placebo-controlled trial of modafinil ( $200 \mathrm{mg} /$ day) for methamphetamine dependence. Addiction 104: 224-233.

Shuman T, Cai DJ, Sage JR, Anagnostaras SG.Interactions between modafinil and cocaine during the induction of conditioned place preference and locomotor sensitization in mice: implications for addiction. Behav Brain Res (2012; 235: 105-112.

Sofuoglu M, Waters AJ, Mooney M (2008). Modafinil and nicotine interactions in abstinent smokers. Hum Psychopharmacol 23: 21-30.

Tahsili-Fahadan P, Carr GV, Harris GC, Aston-Jones G (2010). Modafinil blocks reinstatement of extinguished opiate-seeking in rats: mediation by a glutamate mechanism. Neuropsychopharmacology 35: 2203-2210.

Volkow ND, Fowler JS, Logan J, Alexoff D, Zhu W, Telang F et al (2009). Effects of modafinil on dopamine and dopamine transporters in the male human brain: clinical implications. JAMA 301: 1148-1154.

Wong YN, King SP, Simcoe D, Gorman S, Laughton W, McCormick GC et al (1999). Open-label, single-dose pharmacokinetic study of modafinil tablets: influence of age and gender in normal subjects. J Clin Pharmacol 39: 281-288.

Xi ZX, Newman AH, Gilbert JG, Pak AC, Peng XQ, Ashby CR Jr. et al (2006b). The novel dopamine D3 receptor antagonist NGB 2904 inhibits cocaine's rewarding effects and cocaine-induced reinstatement of drug-seeking behavior in rats. Neuropsychopharmacology 31: 1393-1405.

Supplementary Information accompanies the paper on the Neuropsychopharmacology website (http://www.nature.com/npp) 